\title{
Changes in Use and Perception of Facebook
}

\author{
Cliff Lampe, Nicole B. Ellison, Charles Steinfield \\ Michigan State University \\ 409 CommArts Building, East Lansing MI 48824 \\ lampecli@msu.edu,nellison@msu.edu, steinfie@msu.edu
}

\begin{abstract}
As social computing systems persist over time, the user experiences and interactions they support may change. One type of social computing system, Social Network Sites (SNSs), are becoming more popular across broad segments of Internet users. Facebook, in particular, has very broad participation amongst college attendees, and has been growing in other populations as well. This paper looks at how use of Facebook has changed over time, as indicated by three consecutive years of survey data and interviews with a subset of survey respondents. Reported uses of the site remain relatively constant over time, but the perceived audience for user profiles and attitudes about the site show differences over the study period.
\end{abstract}

\section{Author Keywords}

Social network sites, Facebook, audience, privacy, awareness, use.

\section{ACM Classification Keywords}

H5.3. Information interfaces and presentation (e.g., HCI): Group and Organization Interfaces.

\section{INTRODUCTION}

Increasingly, user participation in social computing systems such as social network sites (SNSs), online communities, and media-sharing sites span multiple years. During this time, the systems can undergo radical redesign, user populations may change, and individual users' social context may evolve. This dynamism inherent in longrunning social computing sites can affect how members of a site use and perceive it.

Others have studied how use changes over time in social computing environments, including early work on MUDs $[5,7]$, online discussion forums $[2,22]$, content creation communities [6] and open source software communities [17], among others. One particular type of social

Permission to make digital or hard copies of all or part of this work for personal or classroom use is granted without fee provided that copies are not made or distributed for profit or commercial advantage and that copies bear this notice and the full citation on the first page. To copy otherwise, or republish, to post on servers or to redistribute to lists, requires prior specific permission and/or a fee.

CSCW'08, November 8-12, 2008, San Diego, California, USA.

Copyright 2008 ACM 978-1-60558-007-4/08/11...\$5.00. computing platform that has grown in use and reach recently is the social network site [3].

While the body of research related to SNSs has been growing over the past several years, change in use of these sites over time has not been addressed. Specifically, this paper examines changes in use and perception of the SNS Facebook amongst members of a public university over the past several years. Facebook is a compelling site to study in that it shares the characteristics of the SNSs described below and has achieved near ubiquity on U.S. college campuses in a relatively short amount of time.

Social computing systems, which include SNSs, are increasingly becoming spaces where many users interact over long periods of time. Understanding and designing for sustained use in social computing systems becomes essential as they become a more prevalent piece of the interaction landscape.

\section{Previous Work on Interactions in Social Network Sites}

Previous research has examined how networked computing systems affect offline social networks [23, 24], but recently there has been increased use of systems specifically designed as social network tools. boyd and Ellison [4] define three main characteristics of SNS: such sites allow users to "(1) construct a public or semi-public profile within a bounded system, (2) articulate a list of other users with whom they share a connection, and (3) view and traverse their list of connections and those made by others within the system." Popular SNSs include MySpace, Facebook, and LinkedIn, among many others. boyd and Ellison [4] summarized the history of these sites, and Hargittai [15] analyzed the demographic characteristics that predict usage of these sites, finding that ethnicity and income levels among other factors can affect the choice of SNS. Gilbert, Karahalios and Sandvig [12] studied differences in rural and urban MySpace users and found that rural users had fewer ties in their networks, among other differences.

There has also been a good deal of research on Facebook as one instance of an SNS. Gross and Acquisti [14] described Facebook use at Carnegie Mellon University and showed that users at that time were unconcerned about privacy implications of SNS use in general and Facebook use in particular. Lampe, Ellison and Steinfield [19] analyzed Facebook profile elements using Donath's signaling framework [9] and found that hard-to-fake signals like addresses and the existence of photos were associated with 
outcomes such as more articulated friendships. Ellison, Steinfield and Lampe [10] also looked at the social capital implications of Facebook use amongst college students, and found that certain types of Facebook use were associated with higher levels of social capital (benefits received from individuals in one's network), perhaps because the site allowed users to maintain broader sets of weak ties in their social networks. Golder, Wilkinson and Huberman [13] examined messages and "pokes" sent on the Facebook network, using data collected directly from Facebook servers between February 2004 and March 2006. They described the temporal patterns of Facebook messages, and concluded that Facebook was becoming an increasingly prevalent means by which college-age members communicate. DiMicco and Millen [8] found that Facebook users transitioning from college to corporate settings employed various strategies to change their Facebook profiles, including making new profiles more appropriate for their new context, erasing all information from profiles, or not making any changes to their profiles. Joinson [16] examined Facebook use employing a Uses and Gratifications theoretical lens and found heterogeneous uses of Facebook. The most common uses were keeping awareness of contacts, sharing photos, organizing groups and participating in applications. The author constructed seven dimensions of use based on factor analyses of survey responses. Lampe, Ellison and Steinfield [18] found that Facebook users searched for people with whom they had a previous offline relationship, and that their anticipated audience was comprised of peers rather than non-peer members of networks (professors, administrators) or people outside networks (law enforcement, employers).

\section{Research Questions}

The findings summarized above lead to several propositions regarding Facebook use. Facebook is an important tool for interaction, particularly among college-aged people [14, 18]. Use of Facebook is heterogeneous among users [16] and changes as individuals move from one life stage or social context to another [8]. However, most of these studies are based on snapshots of Facebook use at a particular moment. Given the rapid growth of this site in terms of users and features, we expect that use and perception of the site has changed over time as well.

RQ1: How has reported use of Facebook to interact with other members changed over time?

In 2006 [18] we found that Facebook users were, in general, reifying existing offline networks, rather than forging new relationships online. One question this research seeks to answer is whether this trend changes over time? Additionally, we wish to discover whether, if change does occur, whether it is because populations are changing their behavior or because new members with different behaviors are entering the site. Norms for how a site like Facebook is used might change, or new users entering a site might engage in different behaviors than veteran users. The addition or removal of features may affect the user experience as well. Over the time period reported in this study, Facebook has added many new features (reported in more detail below) and some of these features were designed to affect social patterns on the site. The interplay between social and technical systems on Facebook may play a large part in how users change their perceptions of the site.

RQ2: How has the perception of audience on Facebook changed over time?

Perception of audience has been a central theme for CSCW research in the past. The constrained information channels that restrict knowing your audience have led to innovations in making audience visible [11] and research on the possible benefits of "lurkers" [21]. In previous work [18], users were asked who they thought had seen their Facebook profile, and in general reported their expected audience was comprised of peers (friends, people in classes, high school acquaintances) and was much less likely to include nonpeers (faculty, family, law enforcement). Since that time, two changes have occurred which might influence users' perceptions of audience. First, in 2006 Facebook introduced a significant change to the interface of the site: a "News Feed" which tracked changes to Friends' profiles and aggregated them in one, highly visible place. This window into peers' activities may have made users more aware of the visibility of their own online activities, thus prompting changes in perceptions of audience (and, perhaps, privacy settings). Additionally, a number of popular press stories focused attention on Facebook use, as did University responses (such as guidance about online self-presentational strategies) to Facebook use by students. These changes in context could affect how Facebook users perceive their audience. Changes in perception of audience may affect how users behave within the site. If they see their audience as more public, they may disclose less about themselves or become more dissatisfied with their use of the site.

RQ3: How have the attitudes of users towards Facebook changed over time?

Previously, we showed that Facebook members largely believed that their profiles portrayed them both accurately and positively [18]. In looking at changes in the relationship between users and a site like Facebook, it may be that use over time leads to changes in how the user perceives the site itself. Moreland and Levine's [20] model of group socialization posits that members of a group are constantly evaluating the value of membership in that group. One might expect, as non-university users join the site and public narratives highlight the risks of Facebook use, that users would change their evaluation of Facebook.

\section{METHODS}

To address the questions raised above, we fielded surveys in 2006, 2007 and 2008. Each year a new random sample of undergraduates at Michigan State University were 


\begin{tabular}{|r|r|r|r|}
\hline Year & Invited & Completed & Response Rate \\
\hline 2006 & 800 & 288 & $36 \%$ \\
\hline 2007 & 1987 & 468 & $24 \%$ \\
\hline 2008 & 1997 & 419 & $21 \%$ \\
\hline
\end{tabular}

Table 1: Response rates for cross-sectional surveys.

invited to participate. Additionally, in April and May of 2007 we conducted interviews with a subset of survey respondents to ask more in-depth questions about use and perceptions of Facebook. These rich qualitative data provide insight into trends identified by the survey data.

\section{Surveys}

Surveys were conducted in 2006, 2007 and 2008 with randomized samples of MSU undergraduate students. Faculty, staff and graduate students of MSU were not sampled. Samples were drawn from the university registrar, and invitations to participate in a Web survey

\begin{tabular}{|c|c|c|c|}
\hline & $\begin{array}{c}2006 \\
(\mathrm{~N}=\mathbf{2 8 8})\end{array}$ & $\begin{array}{c}2007 \\
N=(468)\end{array}$ & $\begin{array}{c}2008 \\
(\mathrm{~N}=419)\end{array}$ \\
\hline & $\begin{array}{c}\text { Mean/\% } \\
\text { (N) }\end{array}$ & $\begin{array}{c}\text { Mean/\% } \\
(\mathrm{N})\end{array}$ & $\begin{array}{c}\text { Mean/\% } \\
(\mathrm{N})\end{array}$ \\
\hline \multicolumn{4}{|l|}{ Gender } \\
\hline Male & $\begin{array}{r}34 \% \\
(98)\end{array}$ & $\begin{array}{r}33 \% \\
(155)\end{array}$ & $\begin{array}{r}37 \% \\
(254)\end{array}$ \\
\hline Female & $\begin{array}{r}66 \% \\
(188)\end{array}$ & $\begin{array}{r}67 \% \\
(312)\end{array}$ & $\begin{array}{r}63 \% \\
(265)\end{array}$ \\
\hline Age & $\begin{array}{r}20.2 \\
\mathrm{sd}=1.64\end{array}$ & $\begin{array}{r}20.6 \\
\mathrm{sd}=2.33\end{array}$ & $\begin{array}{r}20.5 \\
\mathrm{sd}=1.99\end{array}$ \\
\hline \multicolumn{4}{|l|}{ Ethnicity } \\
\hline White & $\begin{array}{r}87 \% \\
(247)\end{array}$ & $\begin{array}{r}79 \% \\
(370)\end{array}$ & $\begin{array}{r}82 \% \\
(342)\end{array}$ \\
\hline Non-White & $\begin{array}{l}13 \% \\
(36)\end{array}$ & $\begin{array}{r}21 \% \\
(84)\end{array}$ & $\begin{array}{l}18 \% \\
(75)\end{array}$ \\
\hline Year in School & $\begin{array}{r}2.55 \\
\mathrm{sd}=1.07\end{array}$ & $\begin{array}{r}2.71 \\
\mathrm{sd}=1.11\end{array}$ & $\begin{array}{r}2.69 \\
\mathrm{sd}=1.174\end{array}$ \\
\hline \multicolumn{4}{|l|}{ Residence } \\
\hline In-state & $\begin{array}{r}91 \% \\
(259)\end{array}$ & $\begin{array}{r}92 \% \\
(428)\end{array}$ & $\begin{array}{r}88 \% \\
(368)\end{array}$ \\
\hline Out-of-state & $\begin{array}{l}09 \% \\
(25)\end{array}$ & $\begin{array}{l}08 \% \\
(36)\end{array}$ & $\begin{array}{l}12 \% \\
(48)\end{array}$ \\
\hline $\begin{array}{l}\text { Fraternity or } \\
\text { sorority member }\end{array}$ & $\begin{array}{r}08 \% \\
(23)\end{array}$ & $\begin{array}{r}09 \% \\
(42)\end{array}$ & $\begin{array}{r}09 \% \\
(38)\end{array}$ \\
\hline$\%$ FB members & $\begin{array}{r}94 \% \\
(268)\end{array}$ & $\begin{array}{r}94 \% \\
(440)\end{array}$ & $\begin{array}{r}96 \% \\
(404)\end{array}$ \\
\hline
\end{tabular}

Table 2: Demographic changes in sample of MSU Facebook users over time. were emailed to the university email addresses of potential respondents. The survey was hosted on Zoomerang, a commercial web survey service. All surveys were conducted in April of the year reported. Typical field period for each survey was two weeks. The surveys were done in an iterative cross-sectional model, where the same population was randomly sampled each year. Table 2 shows changes in the demographics of our respondents. The variable "Year in School" is coded so that lower numbers equate to earlier years in college. In 2006, the "Hours Internet Use/day" was asked in a different format, and data have been converted to be consistent. Numbers in individual cells may not equate to the number of respondents reported per year due to item non-response.

\section{Interviews}

Interviews were conducted with a group of respondents to the 2006 survey reported above. Respondents were interviewed in the spring of 2007. A total of 18 respondents were interviewed: 8 male and 10 female participants. Data were collected using audio recordings that were subsequently transcribed. Using Atlas.ti, a qualitative data analysis program, coders identified themes in the data.

\section{Facebook Feature Changes over Time}

Many interface changes were made to Facebook during the time period covering the studies. Since these features may affect the social processes reported here, the following includes a timeline of major Facebook interface changes.

- May 2006 - Networks are expanded to workplaces as well as colleges and high schools.

- September 2006 - News Feed and Mini-Feed are added, aggregating profile changes of friends. New privacy settings are made available. Additionally, registration is expanded so anyone can join.

- May 2007 - Facebook launches their "Applications" platform.

- July 2007 - Facebook removes the profile field that allows users to list their courses.

- $\quad$ March 2008 - New privacy controls are added.

\section{RESULTS}

\section{Changes in Facebook Uses over Time}

As stated above, one method of exploring Facebook participation over time is to examine the types of uses people report they engage in. In 2006 [18] we found that people were largely using the site to articulate their offline relationships. Joinson [16] showed that people had heterogeneous patterns of use for different features of Facebook. Here, we are interested in how people describe their use of Facebook to make connections: whether they are searching for people online to form a relationship with, 


\begin{tabular}{|l|r|r|r|r|r|r|r|}
\hline Year of survey & \multicolumn{2}{|c|}{2006} & \multicolumn{2}{|c|}{2007} & \multicolumn{2}{|c|}{2008} \\
\hline "I use Facebook to..." & \multicolumn{1}{|c|}{ F } & Mean & $\begin{array}{c}\text { Std. } \\
\text { Dev. }\end{array}$ & Mean & $\begin{array}{c}\text { Std. } \\
\text { Dev. }\end{array}$ & Mean & $\begin{array}{c}\text { Std. } \\
\text { Dev. }\end{array}$ \\
\hline Find people to date & 2.34 & 1.48 & 0.870 & 1.53 & 0.865 & 1.62 & 0.952 \\
\hline Meet new people & 2.18 & 1.97 & 1.027 & 2.13 & 1.154 & 2.14 & 1.116 \\
\hline Check out someone I met socially & 6.92 & 3.99 & 1.053 & $4.17^{1}$ & 0.851 & $3.94^{1}$ & 0.887 \\
\hline Learn more about other people in my classes & 4.21 & 3.26 & 1.204 & $3.49^{1}$ & 1.114 & 3.32 & 1.068 \\
\hline Learn more about other people living near me & 0.63 & 2.86 & 1.218 & 2.97 & 1.248 & 2.95 & 1.149 \\
\hline To keep in touch with old friends & 3.86 & 4.42 & 0.861 & $4.58^{1}$ & 0.684 & 4.50 & 0.671 \\
\hline & & & & & & & \\
\hline Number of Facebook Friends & 37.51 & 201 & 114 & $308^{1}$ & 215 & $333^{2}$ & 227 \\
\hline Minutes per day on Facebook & 22.77 & 28 & 36 & $83^{1}$ & 152 & $82^{2}$ & 117 \\
\hline
\end{tabular}

Table 3: Responses to the question "I use Facebook to..." rated on a Likert scale for likeliness, where higher values equate to more likely to engage in the activity. A mean reported with a " 1 " superscript indicates a significant ( $p<.05$ or better) difference with the vear before. A " 2 " indicates a significant difference between 2006 and 2008.

or are articulating their offline networks in an online environment.

\section{Facebook use remains consistent over time}

Table 3 reports the means and standard deviations of Likert scale responses to questions about Facebook use among the randomly sampled participants in each year of the study. Patterns of use remained consistent with those reported in 2006 [18], with only a few users reporting that they used Facebook to make connections with people they didn't already know. Independent samples ANOVA tests were run comparing the data to determine if differences between years were statistically significant. In addition, a Tukey's post-hoc test was conducted to determine whether there were statistically significant differences between individual years, allowing us to compare 2006 data against both 2007 and 2008. In addition to the items about Facebook use, we also include self-reports of mean time spent per day on Facebook and number of Facebook friends.

The measures regarding using Facebook to meet previously unknown people remained low and stable in all three iterations of the survey. "I use Facebook to find new people to date" and "I use Facebook to meet new people" both average in the low range of the scale. This could be because all users generally see themselves as unlikely to do this, or that a certain minority of users utilize Facebook to meet new people. There could also be a social stigma to answering positively to these questions, leading to an instrument effect. During interviews, respondents denied using Facebook to find new people with whom to socialize, though they did report that they used Facebook heavily to find out more about people they expected to socialize with in the future. One interview respondent mentioned that before a date he would find out more about his partner to subtly integrate things she liked into the date.
Agreement with "I use Facebook to check out someone I met socially" went up between 2006 and 2007, but in 2008 dropped back to 2006 levels. Additionally, during this time there was a slight increase in agreement with the statement "I use Facebook to learn more about people in my classes." This change was not significant between 2007 and 2008. This may be due to a change in the Facebook interface that occurred in July of 2007, when Facebook removed a field that allowed users to list courses they were taking, facilitating the ability for users to find others in their courses and view their profiles. Without this field, it became much harder to do this, especially in large classes. Since this measure has tended toward the middle of the scale with high standard deviations, it could be that there are vastly different strategies that users employ for seeking information on classmates.

Agreement with "I use Facebook to keep in touch with old friends" which started out as a prevalent response in 2006, grew by a significant amount in 2007 , and remained stable into 2008. In both 2007 and 2008 the responses tend to the top of the scale, with little room for more positive change in responses.

The reported number of Facebook friends and time spent using Facebook saw a significant increase between 2006 and 2007, while 2008 remained relatively the same as 2007. This pattern could result from a maturation of use over time. As one interview respondent reported, when she first started using Facebook there was a rush to add friends and seek out information on profiles. After the major part of a person's offline network has been added, use seems to tend to be more about maintenance of the established network. 


\begin{tabular}{|l|r|r|}
\hline Year joined FB & \multicolumn{1}{|c|}{$\mathbf{2 0 0 4}$} & \multicolumn{1}{c|}{$\mathbf{2 0 0 7}$} \\
\hline Find people to date & $\begin{array}{r}1.44 \\
\mathrm{sd}=0.721\end{array}$ & $\begin{array}{r}1.76^{*} \\
\mathrm{sd}=1.031\end{array}$ \\
\hline Meet new people & $\begin{array}{r}1.84 \\
\mathrm{sd}=0.907\end{array}$ & $\begin{array}{r}2.47^{* *} \\
\mathrm{sd}=1.167\end{array}$ \\
\hline
\end{tabular}

Table 4: Newer FB users more likely to use Facebook to find others. *significant at .05 level. **significant at .01 level.

Newer Facebook members show some use differences Another way Facebook use might change over time is through the addition of new users who engage in a different set of behaviors than older users (as opposed to the entire population adopting new norms of use). To test this scenario, we constrained our dataset to 2008 responses only, and looked at changes in the same questions by users who started Facebook in either 2004 (early adopters, as this is the year Facebook began) or 2007 (late adopters). The two groups show no significant differences on most of the measures reported in Table 3, with two notable exceptions reported in Table 4. Although users still reported they were less likely to engage in behaviors designed to meet new people ("Find people to date" and "Meet new people"), as opposed to other types of Facebook connection activities, new users were significantly more likely to engage in them than longer-term users.

Participants describe many reasons for changes in use Although as a whole individuals' self-reported uses for Facebook were fairly stable, differences did emerge when participants were asked specifically about how their use of Facebook changed over time. For example, in the interviews described above, some participants pointed to very active use initially which became more habitual over time:

"I would say when I first got [Facebook], it was such a novelty that I was on a lot just searching kind of in awe, looking at everyone's profile to see what they're really about. And now after being on it a couple of years, all my close friends, I've looked at their profiles before."

Although for others, the increase in the kind and number of features made the site more compelling:

"[Over time my use of Facebook has] probably increased. The features were -- when I first started, it was all about, you know, friending people, finding out who was on Facebook because it was kind of a big deal, you know? But now, I kind of use it to see what's going on with my friends rather than just friending people. I don't look to expand my friend base. I know I'm not going out there searching people I'm not friends with. I use it now for photos a lot and that wasn't a part of Facebook when I first joined."

For others, however, the increased feature set was a deterrent to use. As one participant explained, "I don't use it as much, and especially -- I know, when I first joined, it was like a year old, or something, and the simplicity of it was nice, but now it is getting way too involved and complex, and it is just hard for me to move around [and] do stuff. So, I don't do a whole lot on it anymore."

And for others, the increased number of users made the site unwieldy: "When there were less people, when I first joined... I would actually read the profiles, because it wouldn't take so long and to keep up on what everyone was doing. But now that, you know, pretty much everyone adds you, it's just it's gotten a little bit overwhelming."

Some respondents also reported that changes in their social situation or stage of life led to changes in their Facebook use. For instance, when participants first joined the University, they were interested in meeting as many other students as possible, but that this desire lessened over time as their social networks stabilized. For some participants, as their academic schedules became more demanding, Facebook became an efficient way to keep track of friends. As one participant explained, "I guess when I first started; I thought it was like cool to have more friends at MSU. Like, oh, yes, I have so and so amount of friends at MSU. And now, it's just like I don't care enough, because now I've been here like three years or whatever. And, I just want to be friends with the people that I'm actually friends with."

\section{Changes in Perceptions of Audience and Privacy}

Participation in a site like Facebook may be dependent on the specific audience that is anticipated by those who are using the site. Especially given the growing narrative of "literacy" about the public nature of sites like Facebook we would expect changes in both expectations of privacy and audience over time. In 2006, we reported that users largely considered their peers as their audience, and didn't expect even other who shared their networks, such as professors, to view their profiles.

Table 5 suggests that the populations at MSU who use Facebook are changing their perspectives of audience over time, although not always in obvious ways. In Table 5, the Chi-Square $\left(\mathrm{X}^{2}\right)$ number shows the degree of statistical difference between each year. A higher number indicates a more statistically significant difference.

The data verify the pattern of offline-to-online directionality noted elsewhere [18] regarding how users perceive Facebook audiences. Groups that shared obvious offline connections, like friends and acquaintances, were more likely to be seen as an audience over those who were either not connected offline (strangers) or those who were not peers (such as faculty).

Although many of the categories of anticipated audience remained constant over the three surveys, some changed significantly. In 2008, more users reported that high school friends had viewed their profiles. There was a large drop from 2006 to 2007 in the expectation that a "total strangers from MSU” would view one's profile. This pattern may be 


\begin{tabular}{|l|r|r|r|r|}
\hline & 2006 & 2007 & 2008 & $\mathrm{X}^{2}$ \\
\hline $\begin{array}{l}\text { My high school } \\
\text { friends }\end{array}$ & $90 \%$ & $86 \%$ & $94 \%$ & $25.31^{* * *}$ \\
\hline $\begin{array}{l}\text { Friends other than } \\
\text { HS friends }\end{array}$ & $84 \%$ & $81 \%$ & $87 \%$ & $5.92^{*}$ \\
\hline $\begin{array}{l}\text { People in my } \\
\text { classes }\end{array}$ & $84 \%$ & $78 \%$ & $83 \%$ & 5.15 \\
\hline $\begin{array}{l}\text { Someone I met at a } \\
\text { party or social } \\
\text { event }\end{array}$ & $73 \%$ & $70 \%$ & $72 \%$ & 0.88 \\
\hline $\begin{array}{l}\text { Total strangers } \\
\text { from MSU }\end{array}$ & $74 \%$ & $57 \%$ & $55 \%$ & $28.73^{* * *}$ \\
\hline Family members & $49 \%$ & $54 \%$ & $70 \%$ & $39.58^{* * *}$ \\
\hline $\begin{array}{l}\text { Total strangers } \\
\text { from other } \\
\text { campuses }\end{array}$ & $35 \%$ & $30 \%$ & $28 \%$ & 3.98 \\
\hline $\begin{array}{l}\text { Total strangers } \\
\text { who aren't } \\
\text { affiliated with any } \\
\text { college or school }\end{array}$ & $14 \%$ & $22 \%$ & $24 \%$ & $10.97^{* *}$ \\
\hline $\begin{array}{l}\text { My MSU } \\
\text { professors }\end{array}$ & $12 \%$ & $15 \%$ & $15 \%$ & 1.56 \\
\hline Law enforcement & $6 \%$ & $7 \%$ & $6 \%$ & 0.52 \\
\hline Future employers & $\mathrm{N} / \mathrm{A}$ & $13 \%$ & $18 \%$ & $53.90^{3}$ \\
\hline
\end{tabular}

Table 5: Responses to the question "Since you have created your profile, who do you think has looked at it?" over three surveys. ${ }^{*} \mathbf{p}<.05, * * \mathbf{p}<.01, * * * \mathbf{p}<.001$

explained by two major interface changes that occurred between the two surveys; the first being the creation of the News Feed, and the second being the removal of the "browse network" option. As discussed later, this decrease in perceived profile views by total strangers at MSU mirrors changes in privacy settings, whereby significantly fewer individuals in 2007 reported using the default privacy settings.

The expectation that a family member viewed one's profile increased in each year, most likely related to connections made with siblings and cousins through Facebook, as Facebook opened up to members of organizations and eventually, everyone. We suspect that this increase is primarily associated with younger users, although several interview respondents mentioned showing their Facebook profiles to their parents or other family members.

In 2007 and 2008 we asked respondents if they felt future employers had viewed their profiles. The percentage that answered in the affirmative increased significantly between 2007 and 2008, though stayed relatively low as a whole
( $13 \%$ and $18 \%$, respectively). Seniors were twice as likely to report that a future employer had looked at their profile than were first year students, which is understandable in that these individuals were more likely to be applying for jobs. In 2007 and 2008 respondents were asked their agreement with the statement "Facebook is a student only space." In 2007, respondents had a mean score of 3.11 with standard deviation of 1.27, and in 2008 the mean response was 2.83 with a standard deviation of 1.18 . Agreement went down significantly between those two periods $(t=3.14$, $\mathrm{p}<.01$ ), indicating there was a change in perception about the overall audience of the site. However, even in 2008 the mean response is relatively high, given the increasing population of non-students on Facebook, and the announcements about changes in membership in the media.

In the interviews, respondents discussed the fact that employers might be looking at their profile and the source of this impression, which came from a variety of sources including peers, potential employers and university officials.

Participant: "I've had a lot of people just say, or adults say people are using Facebook now as another tool for interviewing and stuff like that, so I wouldn't want a picture of me on Facebook to hinder me from getting a job."

Participant: "I've heard rumors -- many people have told me that employers and people -- admission committees look at your Facebook profiles and see what you put in them. And any pictures of me at a party, I've untagged myself in. I don't really want to convey a message of -- which I'm not a big partier at all -- but I just don't want somebody getting the wrong impression."

Ackerman [1] presented three challenges to privacy management resulting from the use of technical systems: lack of sufficient nuance, lack of social flexibility, and insufficient capacity for ambiguity.

In each survey, we asked users about their privacy settings, using the actual text from the Facebook interface option as response categories. These categories reflected different groups, with the user specifying who could and who could not view their profile. (Later privacy feature changes of the site enabled users to calibrate these settings in more nuanced ways, such as controlling access to specific features or by specific users.) Facebook changed these response categories each year, which drastically altered the language of this item in each iteration of the survey. Therefore, we recoded all responses into a "default" category for those who had the system default selected for their privacy, and "non-default" for those who had made some change to their privacy settings on Facebook. Responses of "I don't know" were assumed to be in the default category. In 2006, 64\% of users had the default settings for privacy. In 2007 , this number dropped to $45 \%$ of users who had the default settings, and by $200848 \%$ of users maintained the default privacy settings. In the 2006 survey, there were no statistically significant differences, 
using the Pearson Chi-Square measure, between users with default privacy and non-default privacy in any of the questions reported in Table 5.

In 2007, users with default privacy settings were less likely to anticipate a family member had viewed their profile than those who had changed their settings, $40 \%$ to $60 \%$ $\left(X^{2}=19.73, p<.001\right)$. Default privacy users were slightly less likely to think someone in their classes had viewed their profile $\left(\mathrm{X}^{2}=3.92, \mathrm{p}<.05\right)$. They were also less likely to think that someone they had met at a social event would view their profile $\left(\mathrm{X}^{2}=8.87, \mathrm{p}<.01\right)$. Although the fact that those with more open privacy settings (the default) anticipate fewer kinds of audiences is seemingly paradoxical, one explanation is that those individuals are less savvy about privacy in general and thus are less likely to adjust their privacy settings and less aware of the true audience of their profile.

Respondents also were asked to express their agreement on a 5 point Likert scale with the statement "I feel concerned about my privacy because of Facebook." In 2006, the average response was 2.88 , in 20072.80 and in 20082.85 , where higher numbers would indicate more agreement. The means between years did not change significantly.

This neutral stance regarding the privacy implications of Facebook use was also commonly expressed in interviews. Two themes seemed to emerge from interviews. Some users expressed a lack of concern about being judged by their profile. In another prominent theme, users engaged in active management of their profile, as exemplified by the response of one female respondent.

Participant: "There's nothing really on my Facebook profile that ... I wouldn't want a future employer to know anyways. I guess maybe that's just my personality. I'm really open with everything. And if you don't like me for who I am or you don't want me to be, you know, a part of your company because I go out and party with my friends on the weekends, that's kind of ridiculous."

Many respondents mentioned specific strategies for managing their Facebook image, either by constraining the people who see their profile, or by removing elements that they feel would cast them in a negative light.

"INT: You mentioned that you're-your use has become a little more private over time. Was any of that related to the feed when it came ...?

Participant: No, I mean that didn't bother me at all. But, I definitely wipe out my feed, not a lot shows on it. If it does, it's new pictures that I've posted or something like that. But, yes, I've definitely become aware of it, I think as it's gotten a lot bigger. Before, it was so small it didn't really matter and people - but now it's getting a little bit more invasive, so yes, I keep - - that."

\section{User Attitudes towards Facebook}

How have the attitudes of users towards Facebook changed over time? This question addresses changes in how users feel Facebook is as a communication medium, their sense of satisfaction with the site, and concerns they have about their use of the site.

\section{Facebook users are satisfied with the site}

Table 6 reports several attitudinal measures regarding Facebook. Respondents were asked to report the degree to which they agreed with a series of statements, with responses in the form of Likert scale ordinal ratings where higher numbers indicated more agreement. An independent samples ANOVA test was run to determine if there was a significant difference across years. Table 6 reports the $F$ statistic, with a higher number indicating more difference between years. Additionaly, a Tukey's post-hoc test was conducted to determine statistically significant differences between individual years.

The items "Facebook is part of my everyday activity" and "Facebook has become part of my daily routine" probe how regularly respondents view the site, and in all three survey periods they largely agreed with the statement regarding "everyday activity." Respondents also indicated high agreement with two measures asking about the "usefulness" of Facebook, operationalized by the questions "I use Facebook to get useful information" and "I use Facebook to find out about things going on at MSU." While agreement with the statement that "My Facebook use has caused me problems" has grown over the different samples, all responses remain low, with the average response being to "somewhat disagree" with the statement. When asked about whether anything negative had happened to them as a result of their Facebook use, interview respondents described fights with romantic partners, spending too much time on the site, or becoming preoccupied with one's profile and online self-presentation. Many had heard stories from friends, professors, or others about Facebook users losing jobs or opportunities due to content in their profile.

\section{Attitudes towards Facebook change over time}

Users may change their attitudes towards the site over time because of changes in the features offered by the site, or because the population changes as Facebook has allowed more types of members, or a variety of other reasons.

Between 2006 and 2007 several changes occurred in how the respondents in each sample viewed Facebook. All measures of positive attitude towards Facebook increased significantly.

The utility of Facebook seems to be centered on its ability to provide social information about peers or others in one's extended social circle. For instance, one participant who worked as a tutor described how she would use Facebook to look up the profiles of the students she tutored in order to get a better sense of the kind of person they were, and then adjust her tutoring strategies accordingly: 


\begin{tabular}{|l|r|r|r|r|r|r|r|}
\hline Year of survey & & \multicolumn{2}{|c|}{$\mathbf{2 0 0 6}$} & \multicolumn{2}{|c|}{$\mathbf{2 0 0 7}$} & \multicolumn{2}{|c|}{$\mathbf{2 0 0 8}$} \\
\hline & \multicolumn{1}{|c|}{$\mathrm{F}$} & Mean & $\begin{array}{c}\text { Std. } \\
\text { Dev. }\end{array}$ & Mean & $\begin{array}{c}\text { Std. } \\
\text { Dev. }\end{array}$ & Mean & $\begin{array}{c}\text { Std. } \\
\text { Dev. }\end{array}$ \\
\hline Facebook is part of my everyday activity & 36.12 & 3.12 & 1.26 & $3.75^{1}$ & 1.11 & $3.85^{2}$ & 1.12 \\
\hline Facebook has become part of my daily routine & 35.82 & 2.96 & 1.32 & $3.70^{1}$ & 1.16 & $3.66^{2}$ & 1.19 \\
\hline I am proud to tell people I am on Facebook & 2.90 & 3.24 & 0.89 & $3.40^{1}$ & 0.87 & 3.34 & 0.85 \\
\hline Facebook is just a fad & 12.15 & 3.14 & 1.03 & 2.96 & 1.09 & $2.75^{1,2}$ & 1.00 \\
\hline I would be sorry if Facebook shut down & 5.21 & 3.45 & 1.14 & $3.69^{1}$ & 1.19 & $3.72^{2}$ & 1.34 \\
\hline I use Facebook to get useful information & 78.51 & 2.55 & 1.10 & $3.39^{1}$ & 1.02 & $3.54^{2}$ & 1.00 \\
\hline I use Facebook to find out about things going on at MSU & 56.59 & 2.59 & 1.08 & $3.34^{1}$ & 1.18 & $3.51^{2}$ & 1.10 \\
\hline My Facebook use has caused me problems & 22.51 & 1.67 & 0.89 & $2.14^{1}$ & 1.10 & $2.20^{2}$ & 1.12 \\
\hline $\begin{array}{l}\text { I spend time on Facebook when I should be doing other } \\
\text { things }\end{array}$ & 9.44 & 3.16 & 1.15 & $3.52^{1}$ & 1.23 & $3.54^{2}$ & 1.18 \\
\hline
\end{tabular}

Table 6: Ratings of attitudes towards Facebook. A mean reported with a "1" superscript indicates a significant (p<.05 or better) difference with the year before. A "2" indicates a significant difference between 2006 and 2008.

P: I like to find out where they're from, and who I know that they know, too, so that I can kind of like judge them based on who their friends are. I know that's horrible..... And their pictures so I know who they are actually. That's about it.

INT: And would you change your tutoring strategy based on information that you had from Facebook?

P: Yes, I think it's easier to relate to people that you know a little bit about. Like if somebody is from the [Upper Peninsula of Michigan] -- and it's not very diverse up there -- I can kind of gear it towards a non-diverse example when I explain things and stuff like that. So, yes I do.

During interviews, respondents indicated that they were not spending extended periods of time on the site in one session, but rather checked it frequently for updates. This interview exchange was typical:

INT: How often do you log into Facebook?

P: Probably, every day. (laughing)

INT: And, for how long?

\section{P: Not for very long, about a minute or two.}

INT: And, what do you do when you log in?

$P$ : Check to see if I've gotten any message or anything I need to respond to.

However, many participants talked about spending more time on the site during certain periods, especially when they were "bored." When asked how long he spent on Facebook, one participant said, "Maybe ten or fifteen minutes unless I'm bored, and then I'll just look at stuff.... I'll just sit down and like spend an hour just like clicking on people's pictures and what they're doing and all that kind of stuff."

Between 2007 and 2008, changes were not as marked as in the previous period. Facebook appears to have become integrated into participants' daily routines between 2006 and 2007, but then once participants were integrated into the site these gains were not replicated the following year. The News Feed, which was launched in the Fall of 2006, may be a major factor explaining these changes, as it encouraged short sessions with the site that enabled users to quickly see the recent activities of their friends on the site.

\section{DISCUSSION}

This work is concerned with patterns of change in behavior and attitudes in Facebook use among a population. To explore these issues, we return to the initial research questions raised above.

RQ1: How has reported use of Facebook to interact with other members changed over time?

In most ways, there was very little change in Facebook use over time. Users seemed to indicate through both survey and interview responses that they were typically using the site to maintain lightweight contact with relationships they had developed offline. This norm may have evolved in response to Facebook's history, in that the site was initially associated with offline networks like university membership.

It may also be that norms for Facebook use are imported from other sites like previous SNSs, or blogs, and that a "universal" norm for use exists. It could also be that there is a social desirability to certain kinds of perceived use that influences the way users responded to these questions. Regardless, a contribution of this paper is displaying the 
consistency of these reported uses across different samples of users over time.

RQ2: How has the perception of audience on Facebook changed over time?

Many of the findings reported in 2006 [18] remain consistent in terms of the envisioned audience for profiles as perceived by the population of MSU Facebook users. Peers and close online connections are widely seen as the "audience" for these users, as opposed to strangers or very casual acquaintances. Non-peers like faculty, law enforcement, and employers were seldom thought to have viewed profiles. Despite changes in the technical ability of non-university people to join Facebook, there was still the relatively commmon perception that Facebook was a "student-only" site in 2008, though the mean response statistically significantly dropped from the year before.

Some changes in audience perception, for example the drop in anticipation that strangers at MSU had viewed one's profile, may be tied to interface changes. The addition of the News Feed in 2006 and removal of the browse menu between 2006 and 2007 may have influenced expectations of audience. Users may have based their sense of what could be seen about them based on what they could see about others, which may have implications for the design of audience awareness mechanisms. Interview data seems to support that the introduction of the News Feed made respondents more aware of their own information being viewed.

RQ3: How have the attitudes of users towards Facebook changed over time?

Facebook users at MSU reported positive attitudes towards the site. It was widely considered to be part of the daily routine of users, and interview data suggest that users engaged in lightweight contact via the site throughout the course of the day. Users felt they received positive information from the site. Even though mean agreement on the item about whether Facebook caused users problems also went up, interview respondents reported mostly small problems, such as minor embarrassment, and were unable to point to strong negative consequences of their Facebook participation.

In general, over time, users found Facebook more useful and had embedded it into their routines to a greater degree. Especially between 2006 and 2007, users experienced a statistically significant shift in attitudes about the importance of the site. Change from 2007 to 2008 was less significant, and may indicate that users had received the maximum utility from the site, or that further changes (for example the increased use of applications) had confounded advancement in other measures.

\section{Limitations}

The main limitation of this study is the descriptive nature of the results, which makes it impossible to discern causal relationships among the variables we explore. Focusing our analysis on a panel of users and employing more sophisticated multivariate techniques would give us more power to assert the directionality of the relationships we describe.

This study reports findings from undergraduate students at a large public university. It is unreasonable to confidently generalize these results to users with different demographic or cultural contexts. Creating a sampling frame that adequately represents non-college users of Facebook has been a challenge, and needs further development.

Any method comes with costs and benefits, and in this case surveys are powerful means of assessing populations, but rely on self-report which may introduce error into findings. Interviews provide context for use, but are hard to generalize over entire populations. We hope that the combination of methods helps to mitigate weaknesses in individual methodologies.

\section{Future Work}

This work addressed patterns in populations, and this type of cross-sectional survey analysis was appropriate for these questions. A natural extension of this work is to consider changes in individual users. We have collected panel data as well as data from random sample of this population, and plan to do longitudinal analyses in the future that focus on changes in the same group of individuals over time.

Understanding changes in use over time is challenging, as snapshots in time leave gaps in understanding that are hard to resolve after-the-fact. To advance our understanding of interactions in social computing systems in general, and SNSs in particular, research should continue to use multiple methods to paint as complete a picture as possible of interactions in these systems. In this study we used surveys and interviews, but other methods like experimental designs, and analysis of server logs could also be effective in addressing the questions raised here.

\section{CONCLUSION}

Social computing systems as diverse as code repositories, user-generated content sites, large-scale games, and social network sites all depend on the interactions of many participants to realize the full benefits of the system. Describing how participants experience a site and how that experience changes over time helps us understand participation in large-scale systems where many users interact over time.

In our analysis of one of those sites, Facebook, we found that patterns or use, perception and attitude sometimes change over time, though rarely drastically. We speculate that changes, when they do occur, may result from both changes in the user's social context (such as moving to or from college), and perhaps in response to a major change in features, such as the introduction of the News Feed on Facebook. 


\section{ACKNOWLEDGMENTS}

We thank Andrew Smock for his assistance in coding interview data. Thanks to Ying-ju Lai for her help in collecting survey data in 2006 and 2007. Additionally, we would like to thank the College of Communication Arts and Sciences at MSU for its generous support of this research.

\section{REFERENCES}

1. Ackerman, M. The Intellectual Challenge of CSCW: The Gap between Social Requirements and Technical Feasibility. in Carroll, J. ed. Human Computer Interaction in the New Millennium, ACM Press, New York, NY, 2002.

2. Ackerman, M.S. and McDonald, D.W., Answer Garden 2: Merging Organizational Memory with Collaborative Help. in Proceedings of the ACM Conference on Computer-Supported Cooperative Work, (1996), ACM.

3. boyd, d., Friendster and Publicly Articulated Social Networks. in Conference on Human Factors and Computing Systems, (Vienna, Austria, 2004), ACM Press.

4. boyd, d.m. and Ellison, N. Social network sites: Definition, history, and scholarship. Journal of Computer Mediated Communication, 13 (1). article 11.

5. Bruckman, A. MediaMOO: A Professional Community for Media Researchers. Convergence, 1 (1).

6. Bryant, S., Forte, A. and Bruckman, A., Becoming Wikipedian: Transformation of Participation in a Collaborative Online Encyclopedia. in ACM-GROUP, (Sanibel Island, FL, 2005).

7. Churchill, E.F. and Bly, S., Virtual Environments at Work: ongoing use of MUDs in the Workplace. in WACC'99, (San Francisco, CA, 1999), ACM Press, 99108.

8. DiMicco, J.M. and Millen, D.R., Identity management: multiple presentations of self in facebook. in Conference on Supporting Group Work, (Sanibel Island, FL, 2007), ACM Press, 383-386.

9. Donath, J.S. Signals in social supernets. Journal of Computer Mediated Communication, 13 (1). 12.

10. Ellison, N., Steinfield, C. and Lampe, C. The benefits of Facebook "friends:" Social capital and college students' use of online social network sites. Journal of Computer Mediated Communication, 12 (4). article 1.

11. Erickson, T. and Kellogg, W.A. Social Translucence: Designing Systems that Support Social Processes. in Carroll, J. ed. Human-Computer Interaction in the New Millennium, ACM Press, New York, 2002, 325-345.

12. Gilbert, E., Karahalios, K. and Sandvig, C., The Network in the Garden: An Empirical Analysis of
Social Media in Rural Life. in Conference on Human Factors in Computing Systems (CHI), (Florence, Italy, 2008), ACM Press, 1603-1612.

13. Golder, S., Wilkinson, D. and Huberman, B.A., Rhythms of Social Interaction: Messaging within a Massive Online Network. in 3rd International Conference on Communities and Technologies (CT2007). (East Lansing, MI, 2007), Springer.

14. Gross, R. and Acquisti, A., Information Revelation and Privacy in Online Social Networks. in Workshop on Privacy in the Electronic Society, (Alexandria, VA, 2005), ACM Press.

15. Hargittai, E. Whose Space? Differences Among Users and Non-Users of Social Network Sites Journal of Computer Mediated Communication, 13 (1).

16. Joinson, A.N., Looking at, looking up or keeping up with people?: motives and use of facebook. in Conference on Human Factors in Computing Systems (CHI), (Florence, Italy, 2008), ACM Press, 1027-1036.

17. Lakhani, K.R. and Hippel, E.v. How open source software works: "Free" user to user assistance. Research Policy, 32 (6). 923-943.

18. Lampe, C., Ellison, N. and Steinfield, C., A Face(book) in the Crowd: Social Searching vs. Social Browsing. in ACM Special Interest Group on Computer-Supported Cooperative Work, (Banff, Canada, 2006), ACM Press.

19. Lampe, C., Ellison, N. and Steinfield, C., Profile Elements as Signals in an Online Social Network. in ACM Conference on Human Factors in Computing Systems (CHI), (San Jose, CA, 2007), ACM Press.

20. Moreland, R.L. and Levine, J.M. Socialization in small groups: Temporal changes in individual-group relations. Advances in Experimental Social Psychology, 15. 137-192.

21. Nonnecke, B., Preece, J. and Andrews, D., What lurkers and posters think of each other. in 37th Hawaii International Conference on System Sciences, (Hawaii, 2004), IEEE.

22. Smith, M. Measures and Maps of Usenet. in Lueg, C. and Fisher, D. eds. From Usenet to CoWebs: Interacting with Social Information Spaces, Springer Verlag, New York, NY, 2002.

23. Wellman, B. An Electronic Group is Virtually a Social Network. in Kiesler, S. ed. Culture of the Internet, Lawrence Erlbaum, Hillsdale, NJ, 1997.

24. Wellman, B. Which Types of Ties and Networks Give What Kinds of Social Support? Advances in Group Processes, 9. 207-235. 